\title{
Increased and controlled expression of the Rickettsia prowazekii ATPIADP translocase and analysis of cysteine-less mutant translocase
}

\author{
Sherry A. Dunbart and Herbert H. Winkler \\ Aurhor for correspondence: Herbert H. Winkler. Tel : +1 3344606108 . Fax: +1 3344607269 . \\ e-mail: herbertw@sungcg.usouthal.edu
}

Laboratory of Molecular Biology, Department of Microbiology and Immunology, University of South Alabama College of Medicine, Mobile,

AL 36688, USA

\begin{abstract}
Detailed molecular analysis of the Rickettsia prowazekii ATPIADP translocase, an obligate exchange transport system that is specific for ATP and ADP, has been extremely difficult due to limited quantities of material available from these obligate intracytoplasmic bacteria and by the toxicity and poor expression in recombinant Escherichia coli expression systems. In this study, a stable and controllable system for the increased expression of the rickettsial ATPIADP translocase was developed in E. coli where the expression of translocase from the bacteriophage $\mathrm{I7}$ promoter in the PET11a vector led to a 26-fold increase in ATP transport activity and a 34-fold increase in translocase protein as compared to the expression with the native rickettsial promoter in E. coli. When compared to $R$. prowazekii, ATP transport activity was increased sixfold and membrane translocase was increased threefold. Approximately $\mathbf{2 4} \%$ of the translocase protein produced was localized in an inclusion body fraction. This expression system was then used to determine whether the two cysteine residues in the ATPIADP translocase were essential for activity or expression. The translocase was modified by oligonucleotide-directed sitespecific mutagenesis such that the two cysteines were converted to alanines. The ATP transport properties and ATPIADP translocase production kinetics, translocase protein concentration and subcellular localization were indistinguishable in the wild-type and mutant strains, proving that cysteines play no functional role in the R. prowazekif ATPIADP translocase and providing a system suitable for cysteine-scanning mutagenesis.
\end{abstract}

Keywords : rickettsiae, obligate intracellular parasite, ATP transport, cysteine, expression

\section{INTRODUCTION}

Rickettsia prowazekii, the aetiological agent of epidemic typhus, is an obligate intracellular parasitic bacterium which grows directly in the cytoplasm of a eukaryotic host cell. Eukaryotic cytoplasm provides the rickettsiae with an environment rich in preformed metabolites. To take advantage of this unusual ecological niche, the rickettsiae have developed transport systems specific for many of the compounds found in eukaryotic cytoplasm.

Abbreviation: $\beta \mathrm{ME}, \beta$-mercaptoethanol.

†Present address: Department of Pathology, Baylor College of Medicine and Department of Pathology and Laboratory Medicine, Veterans Affairs Medical Center, Houston, TX, USA.
These include not only transport systems which are also exhibited by free-living prokaryotes for substrates such as amino acids (Smith \& Winkler, 1977; Winkler \& Daugherty, 1984) and ions (Winkler, 1984), but also unusual transport systems for complex molecules, including ATP/ADP (Winkler, 1976), AMP (Atkinson \& Winkler, 1985), UDPG (Winkler \& Daugherty, 1986) and NAD (Atkinson \& Winkler, 1989).

The rickettsial ATP/ADP translocase is a carriermediated membrane transport system specific for ATP and ADP (Winkler, 1976). This transport system catalyses the exchange of ATP and ADP through an obligate exchange mechanism, so that for every molecule of ATP that is transported into the rickettsiae a molecule of ADP is expelled into the host cell cytoplasm. The end result of this exchange is the acquisition of a high-energy 
phosphate by the rickettsiae. The translocase from $R$. prowazekii has been solubilized and actively reconstituted into proteoliposomes (Plano \& Winkler, 1989). The gene encoding the $R$. prowazekii ATP/ADP translocase $(t l c)$ has been cloned and expressed in Escherichia coli (Krause et al., 1985), and the sequence determined (Williamson et al., 1989). The translocase protein was identified in immunoblots of SDS-solubilized membranes of $R$. prowazekii and translocase-expressing $E$. coli using antibodies against a synthetic peptide corresponding to the carboxyl-terminal 17 amino acids of the deduced protein (Plano \& Winkler, 1991). These antibodies also bound to inside-out membrane vesicles prepared from translocase-expressing E. coli, but not to right-side-out spheroplasts, localizing the carboxylterminus of the ATP/ADP translocase to the cytoplasmic face of the bacterial inner membrane. In addition, the transport of ATP by both $R$. prowazekii and translocase-expressing $E$. coli was found to be reversibly inhibited by high concentrations of disulfide bond reducing agents (but not thiol reagents), suggesting the presence of an intramolecular disulfide bond in the ATP/ADP translocase that is essential for transport activity (Plano \& Winkler, 1991). These data were used to propose an initial topological model of the $R$. prowazekii ATP/ADP translocase within the lipid bilayer which predicts 12 hydrophobic $\alpha$-helical transmembrane regions with 13 hydrophilic extramembrane domains oriented such that the carboxyl-terminus extends into the cytoplasm, and a putative disulfide bond between Cys37 and Cys85 (which are the only cysteine residues present in the deduced protein sequence).

In this study, a system for increased and stable expression of the ATP/ADP translocase in E. coli was developed utilizing the bacteriophage T7 promoterbased protein expression system (Novagen). Oligonucleotide-directed site-specific mutagenesis was then used to investigate the role of the two cysteine residues in the translocase (Cys37 and Cys85) and the predicted disulfide bond between these residues. In this report we demonstrate that the cysteine-less translocase is fully active and suitable for cysteine-scanning mutagenesis, and that there is no required disulfide bond and no functional role for these two cysteines in the ATP/ADP translocase.

\section{METHODS}

Rickettsial growth and preparation. $R$. prowazekii, Madrid E strain, was propagated in 6-d-embryonated, antibiotic-free hen eggs by inoculation with a dilution of a seed pool (yolk sac passage no. 281) and rickettsial suspensions were prepared as previously described (Winkler, 1976). Further purification, when necessary, was done by a variation of Renografin density-gradient centrifugation (Dasch \& Weiss, 1977; Hanson et al., 1981). Rickettsial suspensions were either used immediately or maintained as frozen stocks at $-80^{\circ} \mathrm{C}$.

E. coli strains, plasmids and culture conditions. E. coli strains and plasmids used in this study are listed in Table 1.
Recombinant clones in host strains DH1 and JM101 were grown at $37^{\circ} \mathrm{C}$ in L broth containing $50 \mu \mathrm{g}$ ampicillin $\mathrm{ml}^{-1}$. Clones in host strain BLR(DE3) were grown in M9 containing $0 \cdot 2 \%$ glucose, a mixture of the 20 amino acids, $50 \mu$ a mpicillin $\mathrm{ml}^{-1}$ and $15 \mu \mathrm{g}$ tetracycline $\mathrm{ml}^{-1}$. Clones in host strain BLR(DE3)pLysS were grown identically except for the addition of $34 \mu \mathrm{g}$ chloramphenicol ml ${ }^{-1}$. Induction of translocase expression was done at $\mathrm{OD}_{600}=0.6$ (Beckman DU50 spectrophotometer) by addition of $1 \mathrm{mM}$ IPTG. E. coli strains were maintained as frozen stocks at $-80^{\circ} \mathrm{C}$ in medium containing $10 \%$ glycerol.

Recombinant DNA techniques. Plasmid vectors were isolated by Wizard Miniprep (Promega) or by caesium chloride gradient centrifugation. DNA fragments used in cloning were purified by GeneClean (Bio101). DNA electrophoresis and general cloning techniques were done by established methodology (Sambrook et al., 1989), and transformation of recombinant plasmids was done according to the method of Nishimura et al. (1990). DNA sequence was analysed by the dideoxy chain-termination method of Sanger et al. (1977) using the Sequenase version 2.0 kit according to the manufacturer's protocol (United States Biochemical).

PCR using the GeneAmp kit (Perkin Elmer Cetus) was used in the construction of plasmids pHW63 and pHW68 to create an NdeI restriction site overlapping the $t l c$ initiation methionine codon. Oligonucleotides Fr (5'GAAAATTTACATATGAGTACTTCC $\left.3^{\prime}\right)$ and Od (5'CCATTTGAAATTAGGATAAGC3') (Oligos Etc.) were used to amplify a 425 bp tlc fragment containing the new NdeI site and an existing ClaI site.

ATP transport assays. Cultures of E. coli were grown to midexponential phase, induced when indicated and harvested by centrifugation at $7741 \mathrm{~g}$ for $10 \mathrm{~min}$ at $4{ }^{\circ} \mathrm{C}$ in a JA-20 rotor (Beckman Instruments). Cell pellets were washed with KP buffer ( $50 \mathrm{mM}$ potassium phosphate, $\mathrm{pH} 7 \cdot 2$ ) and resuspended to a density of 550 Klett units $\mathrm{ml}^{-1}(600 \mathrm{~nm}$ filter; Klett) in KP buffer. Reducing agents and analogues, when used, were preincubated with the cells for $10 \mathrm{~min}$ at room temperature in KP buffer. Removal of these compounds was accomplished by washing the cells twice for $10 \mathrm{~min}$ in KP buffer. Transport was initiated by the addition of $0.1 \mathrm{vol}$. of $\left[\alpha^{32} \mathrm{P}\right] \mathrm{ATP}(1.0 \mu \mathrm{Ci}$; $37 \mathrm{kBq}$ ) in KP buffer (final ATP concentration of $10 \mu \mathrm{M}$ unless otherwise noted). To determine the rate of transport, $100 \mu \mathrm{l}$ aliquots were removed at various times and filtered on prewetted membrane filters (HAWP 02500; Millipore). The filters were washed once with KP buffer, resuspended in $5 \mathrm{ml}$ ReadySafe scintillation cocktail (Beckman Instruments) and measured by liquid scintillation spectrometry. The measured radioactivity was calculated to pmol ATP transported and corrected to mg total cellular protein. Protein concentrations were determined by the BCA protein assay system (Pierce) using BSA as a standard. Variability observed between individual ATP transport assays is related to the $\left[\alpha^{32} \mathrm{P}\right] \mathrm{ATP}$; specifically, the level of ATP transport that is measured decreases with increasing age of the radiolabel and is presumably due to the accumulation of inhibitory degradation products. ATP transport measurements of $R$. prowazekii were done identically with the exception that SPG (sucrose/ phosphate/glutamate) buffer was used (Winkler, 1976).

For ATP efflux measurements, cultures of E. coli were prepared and resuspended in KP buffer as described above and then $0 \cdot 1$ vol. of $\left[\alpha^{-32}\right.$ P]ATP $(1 \cdot 0 \mu \mathrm{Ci} ; 37 \mathrm{kBq})$ in KP buffer (final ATP concentration $10 \mu \mathrm{M}$ ) was added and the mixtures were incubated for $10 \mathrm{~min}$ to allow ATP transport to reach steadystate levels. $\beta$-Mercaptoethanol ( $\beta \mathrm{ME})$, dithiothreitol (DTT) 
Table 1. E. coli strains and plasmids

\begin{tabular}{|c|c|c|}
\hline Strain/plasmid & Description ${ }^{*}$ & Source/reference \\
\hline \multicolumn{3}{|l|}{ Strains } \\
\hline BL21(DE3) & $\mathrm{F}^{-}, o m p T h s d S_{\mathrm{B}}\left(\mathrm{r}_{\mathrm{B}}^{-}, \mathrm{m}_{\mathrm{B}}^{-}\right) \mathrm{gal} d c m(\mathrm{DE} 3)$ & Novagen \\
\hline BLR(DE3) & $\begin{array}{l}\mathrm{F}^{-}, \text {ompT hsdS } S_{\mathrm{B}}\left(\mathrm{r}_{\mathrm{B}}^{-}, \mathrm{m}_{\mathrm{B}}^{-}\right) \text {gal dcm } \\
\quad \Delta(\operatorname{srl}-\operatorname{rec} A) 306:: \operatorname{Tn} 10\left(\text { tet }^{\mathrm{R}}\right)(\mathrm{DE} 3)\end{array}$ & Novagen \\
\hline BLR(DE3)pLysS & $\begin{array}{l}\mathrm{F}^{-}, \text {ompT bsdS } S_{\mathrm{B}}\left(\mathrm{r}_{\mathrm{B}}^{-}, \mathrm{m}_{\mathrm{B}}^{-}\right) \text {gal dcm } \\
\quad \Delta(\operatorname{srl}-r e c A) 306:: \operatorname{Tn} 10\left(\mathrm{tet}^{\mathrm{R}}\right)(\mathrm{DE} 3) \text { pLysS }\end{array}$ & Novagen \\
\hline DH1 & $\begin{array}{l}\mathrm{F}^{-}, \text {recA1 endA1 gyrA96 thi-1 hsdR17 }\left(\mathrm{r}_{\mathrm{K}}^{-} \text {, }\right. \\
\left.\mathrm{m}_{\mathrm{K}}^{+}\right) \text {supE44 relA1 }\end{array}$ & CGSC $6040 \dagger$ \\
\hline JM101 & $\begin{array}{l}\text { supE thi } \Delta(\text { lac-pro } A B)\left[\mathrm{F}^{\prime}, \text { traD36 pro } A B\right. \\
\left.\text { lacl }^{\mathrm{q}} \mathrm{Z} \Delta \mathrm{M} 15\right]\end{array}$ & $\begin{array}{l}\text { D. O. Woodł; (Yanisch-Perron } \\
\text { et al., 1985) }\end{array}$ \\
\hline 11BRS & BLR(DE3)pLysS containing pET11a & This study \\
\hline MOB386 & DH1 containing pMW3 86 & $\begin{array}{l}\text { D. O. Woodf; (Williamson et } \\
\text { al., 1989) }\end{array}$ \\
\hline HW28 & JM101 containing $\mathrm{pHW} 28$ & This study \\
\hline HW63B & BL21(DE3) containing pHW63 & This study \\
\hline HW63BR & BLR(DE3) containing pHW63 & This study \\
\hline HW63BRS & BLR(DE3)pLysS containing pHW63 & This study \\
\hline HW68BRS & BLR(DE3)pLysS containing pHW68 & This study \\
\hline \multicolumn{3}{|l|}{ Plasmids } \\
\hline $\begin{array}{l}\text { pBluescript II } \\
\mathrm{KS}(+)\end{array}$ & $\mathrm{Ap}^{\mathrm{R}}$ & Stratagene \\
\hline pCRII & $\mathrm{Ap}^{\mathrm{R}}$ & Invitrogen \\
\hline pET11a & $\mathrm{T} 7$ promoter expression vector, $\mathrm{Ap}^{\mathrm{R}}, \mathrm{lacl}^{+}$ & Novagen \\
\hline pLysS & T7 lysozyme vector, $\mathrm{Cp}^{\mathrm{R}}$ & Novagen \\
\hline pUC19 & $\mathrm{Ap}^{\mathrm{R}}$ & $\begin{array}{l}\text { D. O. Woodł; (Yanisch-Perron } \\
\text { et al., 1985) }\end{array}$ \\
\hline pMW386 & $\begin{array}{l}\text { pUC19 with inserted } 1.6 \mathrm{~kb} X b a \mathrm{I}-H \text { indIII } \\
\text { rickettsial fragment containing the } t l c \\
\text { gene, } \mathrm{Ap}^{\mathrm{R}}, \mathrm{Tlc}^{+}\end{array}$ & $\begin{array}{l}\text { D. O. Woodł; (Williamson et } \\
\text { al., 1989) }\end{array}$ \\
\hline pHW28 & $\begin{array}{l}\text { pUC19 with inserted } 1.6 \mathrm{~kb} X b a \mathrm{I}-H \text { ind III } \\
\text { fragment containing the } t l c \text { gene, } \mathrm{Ap}^{\mathrm{R}} \text {, } \\
\mathrm{Tlc}^{+}\end{array}$ & This study \\
\hline pHW63 & $\begin{array}{l}\text { pET11a with inserted } 1.6 \mathrm{~kb} \mathrm{NdeI-BamHI} \\
\text { fragment containing the } t l c \text { gene, } \mathrm{Ap}^{\mathrm{R}}\end{array}$ & This study \\
\hline pHW68 & $\begin{array}{l}\text { pET11a with inserted } 1.6 \mathrm{~kb} \mathrm{NdeI-BamHI} \\
\text { fragment containing the Ala37/Ala85 tlc } \\
\text { gene, } \mathrm{Ap}^{\mathrm{R}}\end{array}$ & This study \\
\hline
\end{tabular}

* Genotype symbols are as described by Bachmann (1990). tlc and $\mathrm{Tlc}^{+}$refer to the ATP/ADP translocase genotype and phenotype, respectively.

†B. Bachmann, E. coli Genetic Stock Center, Yale University, New Haven, CT, USA.

$\ddagger$ Department of Microbiology and Immunology, University of South Alabama College of Medicine, Mobile, AL, USA.

or KP buffer (control) was added to $5 \%$ final concentration and the incubation continued for $10 \mathrm{~min} .50 \mu \mathrm{l}$ aliquots of the reaction mixtures were filtered as described above and the remainder was diluted 200 -fold into KP buffer, KP buffer containing $5 \% \quad \beta \mathrm{ME}, \mathrm{KP}$ buffer containing $5 \%$ DTT, or the above media plus $250 \mu \mathrm{M}$ unlabelled ATP. To determine the rate of ATP efflux, $2 \mathrm{ml}$ aliquots of the diluted mixtures were removed at various times, filtered, washed and measured by liquid scintillation spectrometry as described above.

Membrane preparations. Renografin-purified rickettsiae and $E$. coli preparations $(10-20 \mathrm{mg}$ total protein) were washed, resuspended in TP buffer $(10 \mathrm{mM}$ Tris $/ \mathrm{HCl}, \mathrm{pH} 7 \cdot 4,0 \cdot 1 \mathrm{mM}$ PMSF) containing DNase and RNase at $10 \mu \mathrm{g} \mathrm{ml}^{-1}$ and disrupted by two passages through a French pressure cell (American Instrument) at $20000 \mathrm{lb} \mathrm{in}^{-2}$ (152 MPa). Unbroken cells were removed by centrifugation at $7741 \mathrm{~g}$ for $10 \mathrm{~min}$ at $4{ }^{\circ} \mathrm{C}$. For isolation of total insoluble protein, the supernatant was removed and ultracentrifuged at $278835 \mathrm{~g}$ for $40 \mathrm{~min}$ at $4{ }^{\circ} \mathrm{C}$ in a TLA-100.2 rotor (Beckman Instruments). For separation of inclusion body and membrane fractions, the supernatant was centrifuged at $15000 \mathrm{~g}$ for $15 \mathrm{~min}$ at $4{ }^{\circ} \mathrm{C}$ to sediment inclusion bodies (Marston \& Hartley, 1990) and then ultracentrifuged as above to sediment the membranes. The inclusion body and membrane pellets were washed in TP buffer and the centrifugations were repeated. Washed inclusion bodies and membranes were resuspended in TP buffer 
containing $10 \%$ glycerol at a protein concentration of $10-20 \mathrm{mg} \mathrm{ml}^{-1}$. Glycerol was added to the remaining supernatant fluid at $10 \%$ final concentration and all fractions were frozen at $-80^{\circ} \mathrm{C}$.

SDSPAGE, electrotransfer and immunostaining of blotted proteins. Protein samples were solubilized in SDS sample buffer, subjected to electrophoresis on $10-15 \%$ gradient polyacrylamide gels using the PhastSystem electrophoresis system (Pharmacia), stained with Coomassie Blue, electrotransferred onto $0.2 \mu \mathrm{m}$ PVDF transfer membranes (Bio-Rad) or $0.2 \mu \mathrm{m}$ nitrocellulose membranes (type BA-S; Schleicher $\&$ Schuell). These membranes were blocked, and immunostained using an anti-peptide antibody preparation specific for the carboxyl-terminal 17 amino acids of the ATP/ADP translocase, alkaline-phosphatase-labelled goat anti-rabbit IgG (Sigma) and the BCIP/NBT substrate system (Kirkegaard and Perry Laboratories) as previously described (Plano \& Winkler, 1991).

Oligonucleotide-directed site-specific mutagenesis. Oligonucleotide HW1 (5'-GATGTTCGCTATTTTATTAAAC$\left.3^{\prime}\right)$, corresponding to nucleotides 182-203 of the $t l c$ coding strand sequence and containing $T$ to $G$ and $G$ to $C$ base changes at positions 189 and 190, was synthesized at the Biopolymer Center (University of South Alabama College of Medicine, Mobile, AL) and purified using the MERmaid Kit (Bio101) according to the manufacturer's instructions. HW1 was used to convert the codon for Cys 37 to a codon specifying alanine (Ala37). Oligonucleotide Vk (5'-GCTTTAAAATATCAGCTAGCTTAAC-3') (Oligos Etc.), corresponding to nucleotides $324-348$ of the tlc gene anticoding sequence and containing $A$ to $C$ and $C$ to $G$ base changes at positions 333 and 334 , was used to convert the codon for Cys85 to a codon specifying alanine (Ala85). Site-specific mutagenesis was done using the Altered Sites in vitro mutagenesis system (Promega) following the procedure described in the manufacturer's protocol. The resulting mutagenized $t l c$ fragments were used to reconstruct an Ala37/Ala85 mutant $t l c$ gene in pMW386 (pUC19 containing $t l c$ ), which was then used as a template for PCR-based mutagenesis as described above.

Enzymes and reagents. Enzymes used in DNA cloning were purchased from Promega and Gibco-BR and used according to the manufacturer's instructions. $\left[\alpha{ }^{32} \mathrm{P}\right] \mathrm{ATP}\left(25 \mathrm{Ci} \mathrm{mmol}^{-1}\right.$; $925 \mathrm{GBq} \mathrm{mmol}{ }^{-1}$ ) was purchased from ICN Biomedicals. Unless otherwise noted, all other materials were purchased from Sigma.

Data analysis. Immunoblots were scanned using a M-105 hand scanner (DAK Industries) and analysed using NIH Image version 1.55. Statistical analysis of data was done by the Student's $t$-test for paired data using Microsoft Excel for Windows version 4.0 .

\section{RESULTS}

\section{Increased expression of the $R$. prowazekii ATP/ADP translocase in $E$. coli}

A 1555 bp NdeI-BamHI fragment containing the tlc gene, modified by PCR-based mutagenesis to contain a NdeI restriction site overlapping the $t l c$ start methionine codon, was ligated behind the $\mathrm{T} 7$ promoter in the pET11a vector (Fig. 1). The recombinant plasmid, pHW63, was transformed into the E. coli BL21 derivatives BLR(DE3) and BLR(DE3)pLysS and the resulting clones were designated HW63BR and HW63BRS, re-
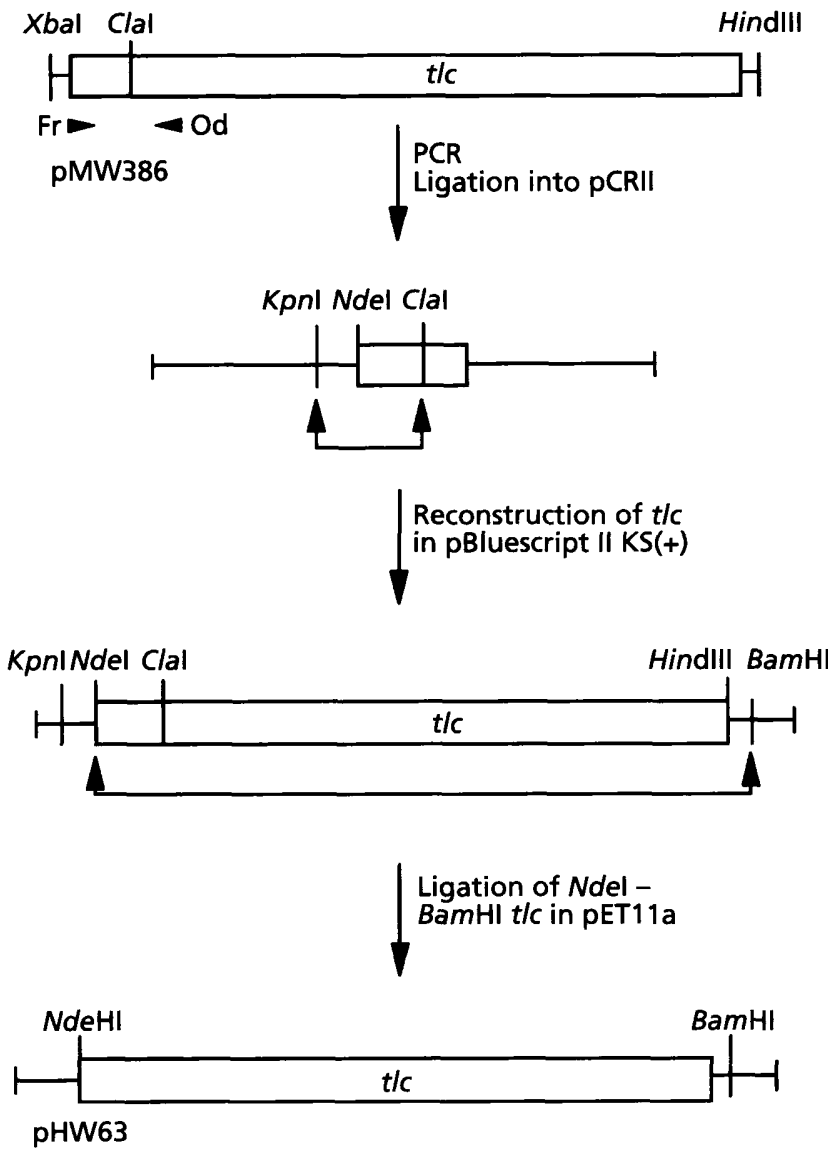

Fig. 1. Construction of pHW63. PCR was used to amplify a $425 \mathrm{bp}$ portion of the t/c gene from pMW386. Primer Fr contained a mutation to create a Ndel restriction site overlapping the t/c start methionine codon. The PCR product was ligated into the pCRII vector. The full-length t/c gene was reconstructed by removing the KpnI-Clal fragment from pCRII and ligating it into pBluescript II $\mathrm{KS}(+)$ containing the $1343 \mathrm{bp}$ Clal-HindIII t/c fragment. The 1555 bp Ndel-BamHI fragment containing the full-length t/c gene was excised and ligated into the pET11a vector to yield pHW63.

spectively. BLR(DE3) contains a recA deletion to increase stability of the $\lambda \mathrm{DE} 3$ lysogen containing the gene for T7 RNA polymerase and BLR(DE3)pLysS also contains the gene for $\mathrm{T} 7$ lysozyme which is expressed in low levels to inhibit basal T7 polymerase activity in the uninduced state.

Expression of the $t l c$ was induced by the addition of $1 \mathrm{mM}$ IPTG and the induced and uninduced translocase levels were measured by ATP transport and immunoblot analysis of whole cells (Fig. 2). In the absence of IPTG, HW63BRS transported $1.8 \mathrm{pmol}$ ATP $\min ^{-1}$ (mg protein $)^{-1}$, which is only slightly greater than the background activity of $1.5 \mathrm{pmol} \mathrm{ATP} \min ^{-1}$ (mg protein) $)^{-1}$ in the vector control strain (11BRS). However, the uninduced level of transport in HW63BR was about fourfold greater (similar to the activity routinely measured in E. coli strains expressing translocase from the native rickettsial promoter) and indicates significant 


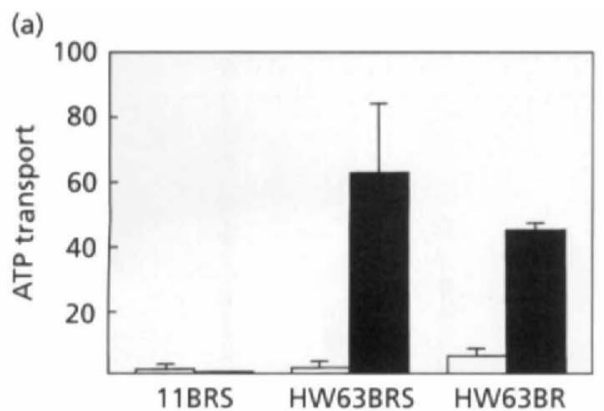

(b)

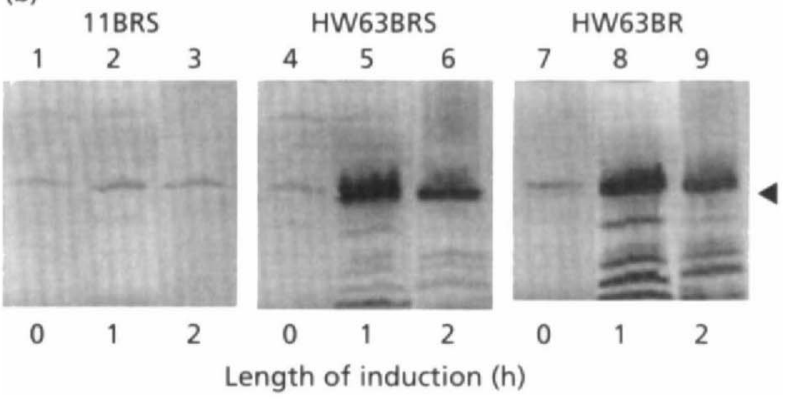

Fig. 2. Expression of ATP/ADP translocase by HW63BR and HW63BRS. (a) ATP transport by HW63BR, HW63BRS and the vector control strain, 11BRS, was measured after 0 (open bars) and $2 \mathrm{~h}$ (filled bars) induction with $1 \mathrm{mM}$ IPTG. Data are the mean and standard deviation of three independent experiments and show pmol ATP transported (mg total cellular protein $)^{-1}$ at $10 \mathrm{~min}$ after addition of [ $\alpha^{32}$ P]ATP. (b) Immunoblot analysis of total cellular protein after induction with $1 \mathrm{mM}$ IPTG for the times indicated. The immunoblots contained $8 \mu \mathrm{g}$ protein per lane. The arrowhead indicates the position of the translocase. The immunoreactive band slightly above the translocase band, visible in lanes 1-4 and 7, corresponds to a major $E$. coli protein visible on CoomassieBlue-stained gels that migrates slightly above the translocase position.

basal expression of translocase prior to induction. After induction with IPTG for $2 \mathrm{~h}$, ATP transport by HW63BRS was 62.4 pmol ATP $\min ^{-1}$ (mg protein) ${ }^{-1}$. The induced level of transport was similar in HW63BR demonstrating that the translocase can be overexpressed in the T7 promoter expression system after IPTG induction.

The basal level of translocase expressed in uninduced HW63BR (lane 7) was visible in immunoblot analysis of whole cells, but no translocase could be visualized in HW63BRS prior to induction (lane 4). Furthermore, there was a decrease in proteolytic degradation of the translocase in HW63BRS upon induction (lanes 5 and 6 compared to lanes 8 and 9). This is probably because the translocase did not accumulate to toxic levels prior to induction, and therefore proteolytic pathways that would degrade the translocase after induction were not activated. The intensity and dimensions of the immunostained translocase band appeared to be greater in HW63BR (lanes 8 and 9) than in HW63BRS (lanes 5 and $6)$, but this was not reflected in the ATP transport activity. This may indicate that a higher percentage of the total translocase is distributed into inclusion bodies in HW63BR. Because of the low level of uninduced expression, HW63BRS was used in all subsequent experiments.

\section{Mutagenesis of cysteines in the ATP/ADP translocase}

To create a cysteine-less (cys-less) mutant translocase and to characterize the requirement for cysteine residues in the translocase, oligonucleotide-directed site-specific mutagenesis was performed on the cloned $t l c$ in E. coli to convert the only cysteines in the molecule, Cys 37 and Cys85, to alanine. Following mutagenesis and reconstruction of the cys-less translocase, DNA sequence analysis verified that the Ala37 mutation (TGT to GCT) and the Ala85 mutation (TGT to GCT) were the only mutations present in the $t l c$ gene. Previous attempts to analyse these mutants in the pUC19-tlc/JM101 expression system demonstrated that the cys-less translocase was active, but revealed an extreme variability in the level of translocase that could be expressed by individual clones and could not be attributed to a particular $t l c$ mutation or pUC19 vector anomaly (data not shown). Because we were unable to regulate $t l c$ expression from the native rickettsial promoter in the pUC19 system, there was no way to equalize the level of translocase expression during cell growth to do quantitative analysis of the effect of the alanine mutations on translocase function. Therefore, the pET11a/ BLR(DE3)pLysS system was used as a controllable expression system for study of the C37A/C85A tlc gene since, without translocase expression during cell growth, there should be no toxicity and no variation in the host cell population prior to induction. The resulting plasmid, pHW68, and the wild-type pHW63 were transformed into competent BLR(DE3)pLysS cells derived from a single isolated colony and the resulting cysless clone was designated HW68BRS.

\section{ATP/ADP translocase activity and protein level in HW63BRS and HW68BRS}

ATP transport activity and translocase protein production in HW63BRS (wild-type tlc) and HW68BRS (C37A/C85A tlc) were compared with that in HW28 (wild-type tlc in pUC19 with a native rickettsial promoter) and $R$. prowazekii (Fig. 3). The ATP transport activities at $1 \mathrm{~min}$ in HW63BRS and HW68BRS were similar, at 26- and 21-fold greater than that in HW28, respectively, and 5.8- and 4.6-fold greater than that in $R$. prowazekii, respectively (Fig. 3a). The membrane and inclusion body translocase concentrations of HW63BRS and HW68BRS were compared with the translocase concentration in the total insoluble fraction of HW28 and $R$. prowazekii by immunoblots of serially diluted samples (Fig. $3 \mathrm{~b}$ ). The mean density per $\mu \mathrm{g}$ protein was calculated and compared to the mean density of $\mathrm{HW} 28$, which was set equal to 1 . The data indicated that there was no significant difference in the amount of translocase in the membranes and inclusion bodies of 
(a)

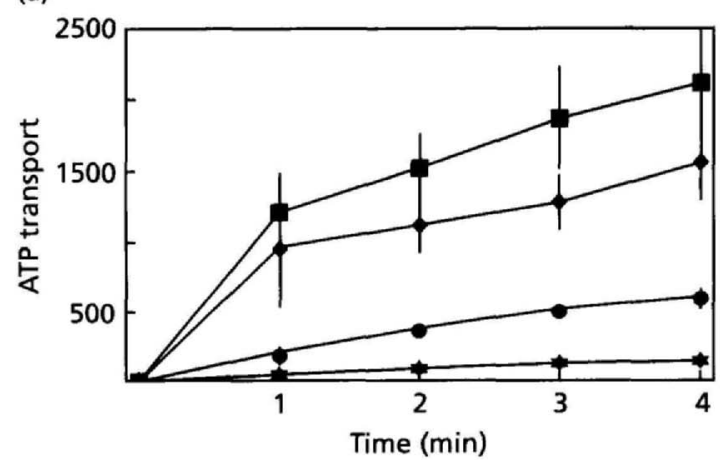

(b)

\begin{tabular}{|lcr|}
\hline Strain & Fraction & Density \\
\hline HW63BRS & M & $26.1 \pm 8.2$ \\
& I & $8.2 \pm 0.2$ \\
HW68BRS & M & $20.5 \pm 6.0$ \\
R. prowazekii & T & $8.5 \pm 1.3$ \\
HW28 & T & 1.0 \\
\hline
\end{tabular}

Fig. 3. ATPIADP translocase expression by HW63BRS and HW68BRS. (a) HW63BRS ( $\square$ ) and HW68BRS $(\bullet)$ were induced for $1 \mathrm{~h}$ with $1 \mathrm{mM}$ IPTG. HW28 $(\star t)$ and $R$. prowazekii $(\bullet)$ were not treated with IPTG. Data are the mean and standard deviation of two to four independent ATP transport assays experiments. ATP transport is given as pmol ATP transported (mg total cellular protein) $)^{-1}$. (b) The membrane (M) and inclusion body (I) fractions from HW63BRS and HW68BRS, and the total insoluble protein fraction (T) from HW28 and $R$. prowazekii were isolated and the ATPIADP translocase was visualized in immunoblots. The density of the translocase band per $\mu \mathrm{g}$ protein in each lane was determined and a mean amount of translocase was calculated by comparison with the mean density in HW28 (indicated as 1).

HW63BRS and HW68BRS. The membrane fraction of HW63BRS and HW68BRS contained 26 $\pm 8-$ and 21 $\pm 6-$ fold more translocase than the HW28 insoluble protein fraction $(P$ values $\leqslant 0.03)$, respectively, and $R$. prowazekii contained $8.7 \pm 0 \cdot 9$-fold more translocase than HW28 $(P$ value $<0.01)$. The inclusion body fractions of HW63BRS and HW68BRS contained $24 \%$ of the total translocase produced, and so, the total translocase produced by HW63BRS and HW68BRS was $34 \pm 8$ - and $27 \pm 7$-fold more than that in HW28, respectively, and $4 \cdot 0 \pm 0 \cdot 9$ - and $3 \cdot 1 \pm 0 \cdot 9$-fold more than that in $R$. prowazekii, respectively $(P$ values $<0 \cdot 05)$.

The cysteine to alanine mutations did not effect either the kinetics of induction or the distribution of translocase between the membrane and inclusion body fractions. In three independent experiments, at 24 (the earliest time at which activity was detectable), 36, 48 and 60 min of IPTG induction the level of ATP transport activity varied between experiments, but there was no significant difference in the overall level of ATP trans-

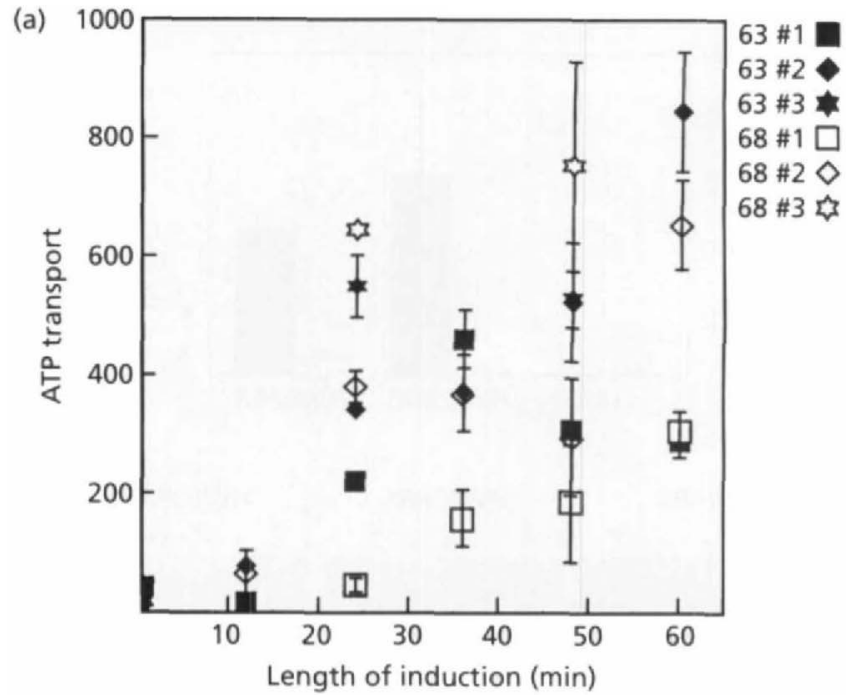

(b)

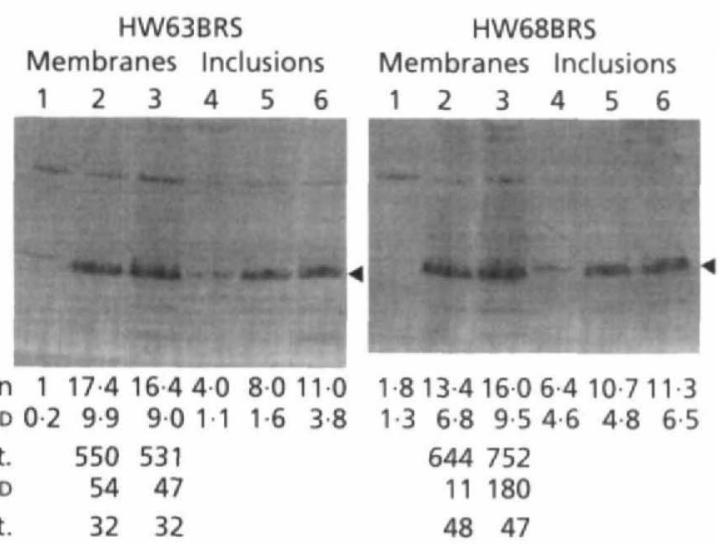

Fig. 4. Induction kinetics of ATP transport activity and translocase protein. HW63BRS (63) and HW68BRS (68) were induced for $0,12,24,36,48$ and 60 min with 1 mM IPTG. (a) ATP transport is represented as pmol ATP transported min $^{-1}$ ( $\mathrm{mg}$ total cellular protein) ${ }^{-1}$ measured at 1, 2 and $3 \mathrm{~min}$ after addition of $\left[\alpha-{ }^{32}\right.$ P]ATP. The data from three independent experiments (\#1, \#2, \#3) are shown with each point representing the mean and standard deviation of three measurements within an experiment. (b) HW63BRS and HW68BRS induced for 0 (lanes 1 and 4), 24 (lanes 2 and 5) and 48 (lanes 3 and 6) min with $1 \mathrm{mM}$ IPTG and the membrane and inclusion body fractions were isolated. The immunoblots shown are representative of three done on the samples from one experiment. The density of the translocase band was determined and compared to the density measured in the same area of the uninduced HW63BRS membrane sample. The mean and standard deviation (SD) of the density measurements, the corresponding ATP transport activity, and the specific activity per amount of translocase are indicated. Arrowheads indicate the position of the translocase. Individual blots are labelled with the strain designations. Densitometric analysis of three independent immunoblots of the membrane and inclusion body fractions from one experiment indicated that similar levels of translocase were produced by both strains and were distributed similarly into membranes and inclusion bodies.

port activity by HW63BRS and HW68BRS (Fig. 4a). The density of the total (the sum of the membrane and inclusion body densities) translocase in HW63BRS and 


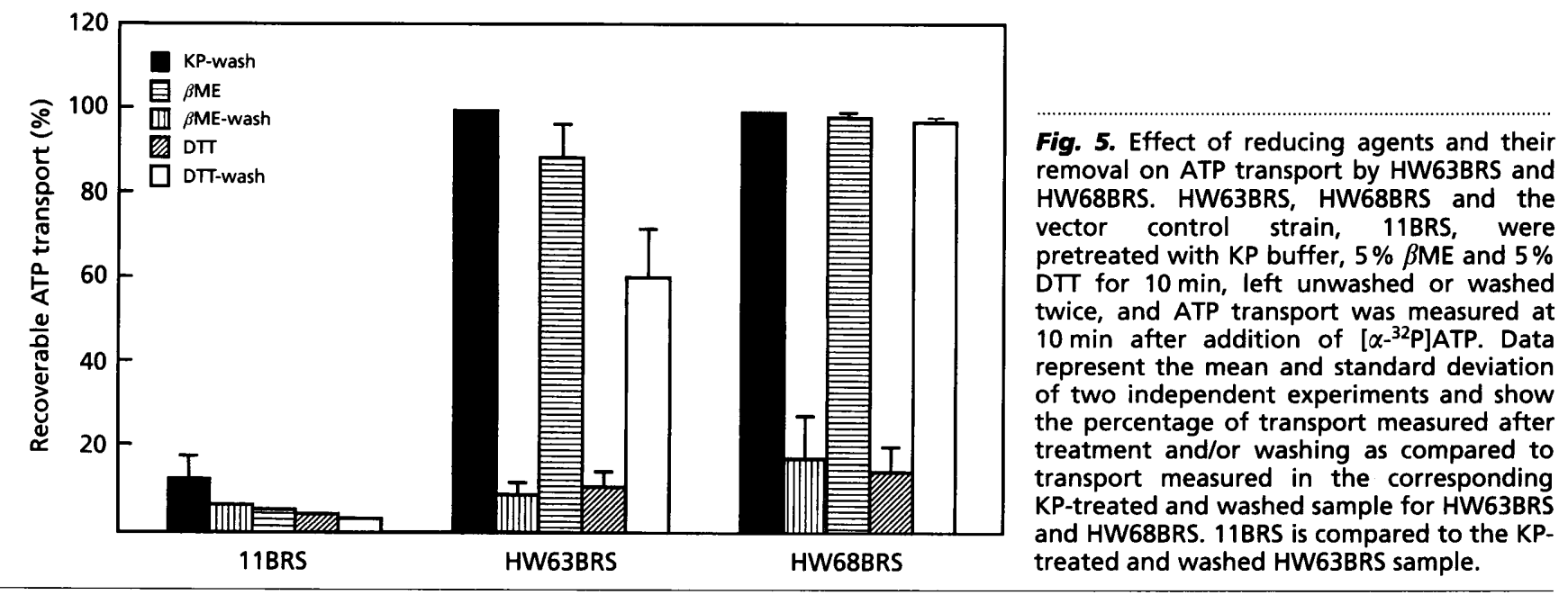

HW68BRS after 24 min induction was $25 \pm 8$ and $24 \pm 8$, respectively, and after $48 \mathrm{~min}$ induction it was $27 \pm 9$ and $27 \pm 10$-fold greater than the density of the same area (below the cross-reactive $E$. coli protein) measured in uninduced HW63BRS membranes, respectively (Fig. $4 \mathrm{~b}$, lanes 2 and 5 and 3 and 6 compared to HW63BRS, lane 1). The inclusion body fractions at these early times after induction contained between 32 and $44 \%$ of the total translocase produced (lanes 5 and 6).

\section{Kinetics of ATP transport by HW63BRS and HW68BRS}

The kinetics of ATP transport by HW63BRS and HW68BRS were determined at $10 \mathrm{~s}$ where the observed rate is approaching a linear, true initial rate of influx. Since HW63BRS and HW68BRS exhibit high transport activity and the efflux of label from the intracellular compartment quickly becomes appreciable, the true $V_{\max }$ of ATP transport is probably higher than can be measured by this assay. The $K_{\mathrm{m}}$ and apparent $V_{\max }$ for ATP transport by the two clones were measured with substrate concentrations ranging from 10 to $200 \mu \mathrm{M}$. ATP influx in HW63BRS and HW68BRS had $K_{\mathrm{m}}$ values of $114 \pm 19$ and $104 \pm 11 \mu \mathrm{M}$, respectively, and apparent $V_{\max }$ values of $6.9 \pm 0.8$ and $6.9 \pm 0.5 \mathrm{nmol} \mathrm{min}{ }^{-1}(\mathrm{mg}$ protein) ${ }^{-1}$, respectively (data not shown). Statistical analysis of the data verified that there was no significant difference in the kinetics of ATP transport by HW63BRS and HW68BRS.

\section{Effect of reducing agents on ATP transport by HW63BRS and HW68BRS}

Interestingly, the uptake of ATP by both the wild-type and cys-less translocases was reversibly inhibited in the presence of high concentrations (those concentrations typically present in gel electrophoresis protocols) of the disulfide reducing agents ( $\beta$ ME and DTT) (Fig. 5). Greater than $60 \%$ of the transport activity, in both clones, could be restored by removal of the reducing agents. The same concentrations of non-reducing analogues of these compounds (ethylene glycol and threitol) had no effect on ATP transport activity (data not shown). To establish that this effect is not due to the reducing agents reversibly permeabilizing the cell membrane (in which case, the translocase would be fully functional, but no transport would be measured due to leakage of the ATP from the cell), the translocasemediated efflux of radiolabelled ATP from loaded bacteria was measured (Fig. 6a). For both strains, greater than $70 \%$ of the radiolabel remained intracellular 10 min after dilution into buffer without exchangeable nucleotide regardless of the thiol reagent treatment used. This indicates that there is little leakage of ATP from the cell. However, when untreated cells were diluted into buffer containing $250 \mu \mathrm{M}$ unlabelled ATP and without thiol reagent (Fig. 6b), the labelled intracellular ATP was rapidly exchanged with the unlabelled extracellular ATP so that less than $15 \%$ of the initial radioactivity remained $10 \mathrm{~min}$ after dilution. In contrast, treated cells (HW63BRS and HW68BRS) diluted into buffer containing $250 \mu \mathrm{M}$ unlabelled ATP and $\beta \mathrm{ME}$ or DTT demonstrated no translocasemediated exchange and the cells retained approximately $60-80 \%$ of the initial radioactivity.

\section{DISCUSSION}

To better understand the molecular mechanisms of ATP/ADP exchange in $R$. prowazekii, a quantity of the ATP/ADP translocase protein sufficient for molecular characterization must be obtained. The amount of ATP/ADP translocase produced in $R$. prowazekii is below the level of detection by SDS-PAGE. Furthermore, the difficulty in propagating this intracytoplasmic parasite limits the quantities of rickettsial material available. Expression of the tlc in E. coli provides an additional, potentially unlimited source of the translocase protein. However, toxicity and poor expression of the translocase protein in E. coli systems (from either rickettsial or E. coli promoters) have made its study extremely difficult. While many prokaryotic and eukaryotic membrane proteins have been overexpressed in E. coli systems so that they constitute up to $60 \%$ of the total 
(a)

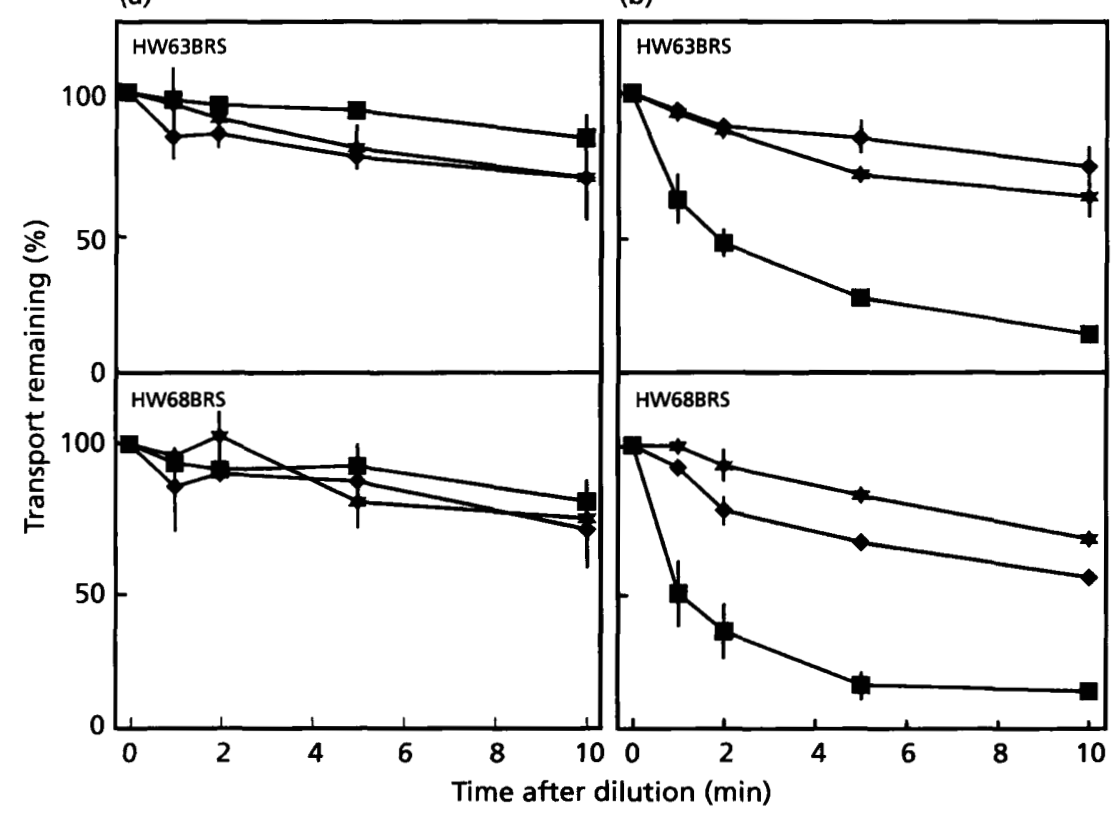

Fig. 6. ATP effiux in the presence of reducing agents in the presence or absence of ATP. HW63BRS (wild-type) and HW68BRS (cys-less) were induced for $1 \mathrm{~h}$ with $1 \mathrm{mM}$ IPTG. The cells were incubated with [ $\left.\alpha-^{32} \mathrm{P}\right]-$ ATP for $10 \mathrm{~min}$, treated with KP buffer $(\square), 5 \% \beta \mathrm{ME}(\downarrow)$ or $5 \% \mathrm{DTT}(\star)$ for $10 \mathrm{~min}$, and ATP efflux was measured after 200 -fold dilution into the same solution either (a) without ATP or (b) with $250 \mu \mathrm{M}$ ATP. inner-membrane protein (Henderson et al., 1992); in many cases, toxicity prevents significant accumulation of the gene product. Basal expression from poorly controlled promoters allows low levels of the toxic protein to accumulate and these low levels are sufficient to prevent establishment of plasmids in E. coli and stable overexpression of cloned genes. Therefore, stable overexpression of cloned genes requires the ability to control expression during cell growth.

Increased, stable expression of the translocase was achieved using the $\mathrm{T} 7$ promoter in the $\mathrm{pET}$ protein expression system. Similar levels of ATP transport activity and translocase protein were obtained upon IPTG induction regardless of the host strain used. This indicates that the translocase can be expressed from the $\mathrm{T} 7$ promoter after induction and that the host cells are adequately able to maintain the $\mathrm{T} 7$ polymerase gene and the tlc during cell growth. In contrast with uninduced expression in HW63BR [host strain BLR(DE3)], no uninduced translocase expression could be measured in HW63BRS [BLR(DE3)pLysS host system], demonstrating that the low level of $T 7$ lysozyme expressed by this strain is sufficient to inhibit basal T7 polymerase activity but has no effect on the high levels of T7 polymerase produced after induction. In addition, proteolytic degradation of the induced translocase was diminished in HW63BRS relative to the other strains, suggesting that proteolytic mechanisms that degrade the translocase are not activated when the translocase cannot accumulate prior to induction. We have referred to the level of expression as increased expression rather than overexpression since this protein cannot be seen on Coomassie-Blue-stained gels. The reasons for the lack of over-expression are unknown and under investigation.

The requirement for cysteine residues in the translocase was characterized using oligonucleotide-directed site- specific mutagenesis to convert the two cysteine residues in the translocase to alanine. The pET1la/ BLR(DE3)pLysS system was utilized as a controllable expression system in which to perform a quantitative analysis of the effect of the alanine mutations on translocase expression and function. The induced ATP transport activity and functional membrane translocase in the wild-type (HW63BRS) and cys-less (HW68BRS) strains were similar at 26- and 21-fold greater than that in a strain expressing $t l c$ from the native rickettsial promoter (HW28), respectively. The data also show that, as compared to $R$. prowazekii, ATP transport by HW63BRS and HW68BRS was increased about fivefold and the membrane translocase concentration was more than twofold higher. Approximately $24 \%$ of the total translocase produced by both HW63BRS and HW68 BRS was found in inclusion bodies, which is a nonfunctional translocase fraction. In addition, there was no statistically significant difference in the kinetics of ATP transport by the wild-type and cys-less translocases with a $K_{\mathrm{m}}$ of ATP influx of about $110 \mathrm{mM}$ and an apparent $V_{\max }$ of $6.9 \mathrm{nmol} \mathrm{m^{-1 }}$ (mg protein) ${ }^{-1}$. The fact that the wild-type and cys-less translocases are produced in equivalent amounts and are equally active with the same ATP transport kinetics demonstrates that the cysteines play no vital functional role in the ATP transport process. Also, there was no significant difference in the level of ATP transport activity by HW63BRS and HW68BRS when measured at 24, 48 and $60 \mathrm{~min}$ IPTG induction. Likewise, at 24 and $48 \mathrm{~min}$ induction, the wild-type and cys-less translocases were produced to the same levels (24-27-fold greater than the uninduced) and were similarly distributed between the membrane and inclusion body fractions $32-44 \%$ ). This indicates that the cysteine to alanine mutations also have no effect on the kinetics of translocase production or the distribution of translocase between the membrane 
and inclusion body fractions. Therefore, the measurement of ATP transport ( $\mathrm{mg}$ total cellular protein) ${ }^{-1}$ is a specific measurement of ATP transport per amount of functional membrane translocase.

Transport of ATP by both the wild-type and cys-less translocases was reversibly inhibited by high concentrations of disulfide reducing agents. This inhibition was not due to permeabilization of the cell membrane by the reducing agents because there was no efflux of radiolabelled ATP from loaded cells diluted into nucleotidefree medium with or without reducing agent treatment. Furthermore, there was no exchange of intracellular radiolabelled ATP with extracellular unlabelled ATP by cells treated with reducing agents, demonstrating that both translocase-mediated ATP influx and efflux are inhibited in the presence of disulfide reducing agents. Because the cys-less translocase is incapable of participating in disulfide bonds, this inhibition cannot be due to disulfide bond reduction within the translocase molecule as previously suggested (Plano \& Winkler, 1991). Hence, the inhibition of ATP transport activity in the presence of reducing agents must be the result of either an indirect effect on the translocase or a property unrelated to the disulfide reduction activity of the reducing agents.

Various thiol reagents are available and can be used to study protein topology by EPR, NMR, diffraction and a variety of other methods. In combination with cysteinescanning mutagenesis, these methods have been used to elucidate the importance of specific residues for transport activity in the E. coli lactose permease (Wu \& Kaback, 1996, and references therein). We intend to use these methods on the cys-less translocase produced by the $\mathrm{pET} 11 \mathrm{a} / \mathrm{BLR}(\mathrm{DE} 3)$ pLysS expression system in future mutagenesis studies to identify the specific amino acids in the ATP/ADP translocase protein which are important for transport activity and to determine the structure-function relationships of this unusual transport system.

\section{ACKNOWLEDGEMENTS}

We thank Robin Daugherty and Rose Robertson for expert technical assistance. This work was supported by Public Health Service grant AI-15035 from the National Institute of Allergy and Infectious Diseases.

\section{REFERENCES}

Atkinson, W. H. \& Winkler, H. H. (1985). Transport of AMP by Rickettsia prowazekii. J Bacteriol 161, 32-38.

Atkinson, W. H. \& Winkler, H.H. (1989). Permeability of Rickettsia prowazekii to NAD. J Bacteriol 171, 761-766.

Bachmann, B. J. (1990). Linkage map of Escherichia coli K-12, edition 8. Microbiol Rev 54, 130-197.
Dasch, G. A. \& Weiss, E. (1977). Characterization of the Madrid E strain of Rickettsia prowazekii purified by renografin density gradient centrifugation. Infect Immun 15, 280-286.

Hanson, B. A., Wisseman, C. L., Jr, Waddell, A. \& Silverman, D. J. (1981). Some characteristics of heavy and light bands of Rickettsia prowazekii on Renografin gradients. Infect Immun 34, 596-604.

Henderson, P. J. F., Baldwin, S. A., Cairns, M. T. C., Charalambous, B., Dent, H. C., Gunn, F. G., Liang, W.-J., Lucas, V. A., Martin, G. E. M. \& MCDonald, T.P. (1992). Sugar-cation symport systems in bacteria. Int Rev Cytol 137, 149-208.

Krause, D. C., Winkler, H. H. \& Wood, D. O. (1985). Cloning and expression of the Rickettsia prowazekii ADP/ATP translocator in Escherichia coli. Proc Natl Acad Sci USA 82, 3015-3019.

Nishimura, A., Morita, M., Nishimura, Y. \& Sugino, Y. (1990). A rapid and highly efficient method for preparation of competent $E$. coli cells. Nucleic Acids Res 18, 6169.

Plano, G.V. \& Winkler, H. H. (1989). Solubilization and reconstitution of the Rickettsia prowazekii ATP/ADP translocase. J Membr Biol 110, 227-233.

Plano, G. V. \& Winkler, H. H. (1991). Identification and initial topological analysis of the Rickettsia prowazekii ATP/ADP translocase. J Bacteriol 173, 3389-3396.

Sambrook, J., Fritsch, E. F. \& Maniatis, T. (1989). Molecular Cloning : a Laboratory Manual, 2nd edn. Cold Spring Harbor, NY: Cold Spring Harbor Laboratory.

Sanger, F., Nicklen, S. \& Coulson, A. R. (1977). DNA sequencing with chain-terminating inhibitors. Proc Natl Acad Sci USA 74, 5463-5467.

Smith, D. K. \& Winkler, H. H. (1977). Characterization of a lysinespecific active transport system in Rickettsia prowazekii. J Bacteriol 129, 1349-1355.

Williamson, L. R., Plano, G. V., Winkler, H. H., Krause, D. C. \& Wood, D. O. (1989). Nucleotide sequence of the Rickettsia prowazekii ATP/ADP translocase-encoding gene. Gene 80, 269-278.

Winkler, H. H. (1976). Rickettsial permeability: an ADP-ATP transport system. J Biol Chem 251, 389--396.

Winkler, H. H. (1984). Potassium permeability of Rickettsia prowazekii. J Bacteriol 157, 197-201.

Winkler, H. H. \& Daugherty, R. M. (1984). Proline transport and metabolism in Rickettsia prowazekii. J Bacteriol 158, 460-463.

Winkler, H. H. \& Daugherty, R. M. (1986). Acquisition of glucose by Rickettsia prowazekii through the nucleotide intermediate uridine 5'-diphosphoglucose. J Bacteriol 167, 805-808.

Wu, J. \& Kaback, H. R. (1996). A general method for determining helix packing in membrane proteins in situ: helices I and II are close to helix VII in the lactose permease of Escherichia coli. Proc Natl Acad Sci USA 93, 14498-14502.

Yanisch-Perron, C., Vieira, J. \& Messing, J. (1985). Improved M13 phage cloning vectors and host strains: nucleotide sequences of the M13mp18 and pUC19 vectors. Gene 33, 103-119.

Received 9 June 1997; revised 28 July 1997; accepted 29 July 1997 